\title{
Papel dos Pais no Desenvolvimento de Jovens Futebolistas
}

\author{
Luiz Carlos Moraes' \\ Universidade Federal de Minas Gerais \\ André Scotti Rabelo \\ Universidade Federal de Minas Gerais; Associação de Ensino Versales \\ John Henry Salmela \\ Universidade Federal de Minas Gerais
}

\begin{abstract}
Resumo
Este estudo investigou o papel dos pais no desenvolvimento de atletas jovens de futebol. Foram voluntários nesse projeto 20 pais e 12 filhos jogadores, entre as idades de 15 e 18 anos, participantes da temporada 2000 do Campeonato Mineiro. Utilizou-se uma abordagem quantitativa e qualitativa, através de formulários, questionários e entrevistas semi-estruturadas de aprofundamento. Constatou-se que os pais tinham pouco envolvimento nos treinamentos e competições dos atletas, não alteraram a rotina familiar em função dos treinamentos dos mesmos. O relativo apoio dos pais não prejudicou o progresso dos filhos devido os pais permitirem os mesmos praticarem o futebol livremente. Outro aspecto importante foi o progresso dos filhos devido à paixão, à intensidade e freqüência de prática, além do apelo financeiro que o futebol profissional evoca no Brasil. Esses resultados indicam a necessidade de precauções quando se considerar paradigmas de primeiro mundo em outras culturas na qual exista restrição contextual.

Palavras-chave: Pais; influências; atletas; futebol; Brasil.
\end{abstract}

\section{Parents Role in the Development of Soccer Players}

\begin{abstract}
This study investigated the role of parents in the development of soccer players. Twenty parents and 12 soccer players, between 15 and 18 years old participated in the study. Both quantitative and qualitative approaches were used by administrating questionnaires forms and interviews. It was observed that few changes occurred in the family routines and that parents were minimally involved in their sons' sport activities. This did not appear to be a constraint for their sons' development because of their passion for soccer, the total amount of practice, and a potential lucrative professional career. Researchers should carefully adopt important paradigms from first world countries to another country with contextual differences.

Keywords: Parents; roles; young; athletes; football; Brazil.
\end{abstract}

Em diferentes áreas, como música, artes plásticas, esporte, ciências exatas, entre outras, os indivíduos que se sobressaem são considerados expoentes. Esses expoentes, também denominados experts, quando investigados em diferentes estudos retrospectivos sobre as suas carreiras, serviram como base para a criação de modelos de desenvolvimento de talentos humanos. Esses modelos de desenvolvimento têm sido estudados principalmente nos países de primeiro mundo (Bloom, 1985; Csikszentmihalyi, Rathunde \& Whalen, 1993).

Outro aspecto que merece destaque é a influência dos pais como parte fundamental no desenvolvimento desses expoentes. Especificamente no esporte, vários autores enfatizam a importância da relação pais-atletas no sucesso da carreira esportiva (Côté, 1999; Durand-Bush \& Salmela,

\footnotetext{
${ }^{1}$ Endereço para correspondência: Av. Pres. Antônio Carlos, 6627, Campus Pampulha, Belo Horizonte, MG, 31270 901. Fax: (31) 34992325. E-mail: lmoraes@ufmg.br
}

2002). Todos esses estudos demonstram o papel crucial dos pais, especialmente durante os anos iniciais de experimentação nos anos de especialização dos atletas. Eles afirmam que quando os atletas recebem um apoio apropriado dos pais, especialmente na infância, há o entiquecimento da participação dos mesmos possibilitando grandes experiências e permanência no esporte.

A pesquisa de Bloom (1985) foi um marco sobre o desenvolvimento do talento no esporte, música e ciência. O estudo demonstra que as pessoas consideradas altamente competentes seguem uma trajetória por diferentes fases, que vão desde os anos iniciais de experiência na atividade, passando pelos anos intermediários, até os anos finais de desenvolvimento. Segundo Bloom, nos anos iniciais, os pais serviam de exemplo para a iniciação no domínio específico, estimulando e criando situações de interesse para os filhos. Por exemplo, no tênis, um esporte da classe média, os pais permitiam seus filhos brincar, descobrir e ter prazer durante o processo. Os pais encorajavam seus filhos, fornecendo 
recursos e materiais, ensinavam as primeiras habilidades na área e lhes proporcionavam acesso aos professores, os quais os introduziam na atividade de maneira prazerosa. Acompanhavam de perto seus filhos, enfatizando o valor do trabalho e ajudandoos na prática diária, proporcionando tempo para atividades com toda a família. Yang, Telema e Laakso (1996) também assinalam que a situação sócio-econômica das famílias não determina a orientação e o sucesso dos atletas no esporte.

Csikszentmihalyi e colaboradores (1993), em estudo longitudinal com jovens talentosos, identificaram a integração, harmonia total da pessoa com a atividade, e a diferenciação através de desafios constantes, como duas outras variáveis necessárias para o desenvolvimento de expoentes. Introduziram também o conceito de complexo familiar para descrever as familias que promoveram os melhores estímulos para o desenvolvimento de seus filhos em diferentes áreas, dentre elas o esporte. Este estudo veio complementar os anteriores, pois a participação da familia é apontada por Bloom (1985) como fator importante nas diferentes fases de desenvolvimento, sendo uma das responsáveis pela superação das restrições impostas pela área de conhecimento.

O trabalho de Davidson, Howe, Moore e Sloboda (1996) com crianças que estudam música, demonstrou a influência do envolvimento dos pais no desenvolvimento da performance na música. As crianças que obtiveram sucesso na aquisição de habilidades musicais tinham um alto grau de apoio dos pais. Quanto maior o interesse e a participação dos pais, melhor era o nível de desenvolvimento dos filhos. Os autores também encontraram um maior envolvimento dos pais à medida que seus filhos progrediam.

\section{Esporte e Pais}

O conceito de envolvimento dos pais no esporte, segundo Hellstedt (1990), é um continum que vai do subenvolvimento ao envolvimento moderado e, por fim, ao superenvolvimento. Hellstedt define o subenvolvimento como uma relativa falta de comprometimento emocional, financeiro ou funcional dos pais, que tem como indicativos a falta de comparecimento a jogos e eventos. Pouco envolvimento em atividades voluntárias (tais como o transporte), pouquíssimo contato com os treinadores. No envolvimento moderado, considerado pelo autor como sendo o ideal, os pais são firmes em suas orientações, dando suporte e ajudando os filhos a estabelecerem metas realísticas, além de serem financeiramente participativos. O superenvolvimento ocorre quando os pais excedem em sua participação na vida esportiva dos filhos, não sabendo separar seus próprios desejos, fantasias e necessidades daquelas dos seus filhos. Hellstedt verificou que baixos níveis de pressão estão relacionados com uma reação positiva dos filhos. Ao contrário, altos níveis de pressão indicam reações negativas. Sugeriu ainda, como problema principal, identificar o nível ideal de pressão que o pais podem exercer sobre seus filhos para que tenham uma reação positiva, tanto no treinamento quanto na competição.

Carlsson (1993) estudou atletas jovens que obtiveram sucesso em diversos esportes, verificando que a iniciação no esporte organizado foi determinada pelos interesses dos pais e dos amigos, geralmente quando a criança tinha entre sete e nove anos. $\mathrm{O}$ autor apontou, também, o apoio dos pais e as atitudes positivas como importantes durante todo o desenvolvimento de atletas jovens. Carr, Weigand e Jones (2000) levantaram outro ponto importante relacionado à participação dos pais no sucesso dos filhos, que é a ajuda para o alcance de metas e crenças no esporte. A definição das metas dos atletas estava relacionada às crenças e percepções de sucesso que os pais tiveram quando praticaram um esporte. Esses achados sugerem que os pais exercem grande influência, pois transmitem suas próprias crenças, influenciando os filhos sobre as razões que levam ao sucesso no esporte e sobre como proceder para alcançar esse objetivo.

Dessa forma, Côté (1999) conduziu um estudo sobre os padrões da dinâmica da família para o desenvolvimento de jovens remadores. Esse estudo contribuiu para uma visão geral do comportamento dos pais, no desenvolvimento do potencial de seus filhos em diferentes fases. $\mathrm{O}$ autor apresentou três estágios de participação no esporte que são: a) anos de experimentação (de 6 a 13 anos), onde pais introduziam os filhos no esporte com ênfase no divertimento, euforia e possibilidade de vivências variadas; b) anos de especialização (de 13 a 15 anos), marcados pelo crescente interesse e comprometimento com o esporte, onde pais enfatizavam produção na escola e no esporte, investindo tempo e dinheiro, tendo ainda irmãos mais velhos como exemplo; e c) anos de investimento (de 15 anos em diante), aumento do compromisso dos filhos e pais demonstrando grande interesse e suporte para superar as dificuldades da progressão do treinamento; sendo estes similares às fases encontradas por Bloom (1985). Destaca-se aqui que o remo é um esporte praticado pela classe média- alta, da mesma forma que foram os esportes estudados por Bloom, como o tênis e a natação. Os pais, no estudo de Côté, também foram apontados como fator determinante para atingir o sucesso, na medida em que davam o apoio emocional necessário, bem como suporte financeiro e logístico. Esse apoio ocorreu durante as várias etapas de transição e as fases da carreira dos atletas, desde a escolha, o desenvolvimento na iniciação esportiva até chegar à participação em competições de alto nível. Isso vem confirmar as discussões de Salmela, Young e Kallio (2000) sobre os períodos marcantes de transição 
como os mais críticos para o sucesso de atletas expoentes no futuro, dependendo das relações da tríade atletatreinador-pais.

\section{Futebol e o Esporte no Contexto Brasileiro}

No futebol, o estudo de Jambor (1999), realizado nos Estados Unidos, apontou os pais como agentes socializadores de seus filhos no referido esporte, demonstrando que, apesar de os pais não terem jogado futebol, a socialização vai além do exemplo físico, tendo estes apoiado o crescente interesse pelo esporte. Ommundsen e Vaglum (1991) encontraram também no futebol para jovens atletas, a presença dos pais como um fator relacionado ao prazer para a prática desse esporte. $\mathrm{O}$ apoio dos pais no futebol, assim como em outros esportes, tem papel fundamental na performance do filho. Van Yperen (1998) estudou jovens jogadores de futebol, altamente habilidosos, quanto ao relacionamento com o grupo, como também diante da possibilidade de serem dispensados ao final da temporada. Os jovens jogadores de futebol só apresentavam problemas com a queda de níveis de performance quando não recebiam suporte dos pais. É interessante saber se no esporte em geral e no futebol, em particular no Brasil, os atletas seguem os mesmos degraus de desenvolvimento com relação ao apoio dos pais, como foi o caso da classe média esportiva descrita por Bloom (1985) e Côté (1999). Essa linha de investigação é parte dos estudos conduzidos por Moraes, Salmela, Rabelo e Vianna Júnior (2000), Vianna Júnior, Moraes, Salmela e Mourthé (2001) e Moraes, Salmela, Rabelo, Lima e Lôbo (2001) com atletas e sobre a influência dos pais em jovens jogadores de futebol, ginástica rítmica desportiva e voleibol.

Com relação ao papel dos pais de atletas da ginástica rítmica desportiva, Vianna Júnior e colaboradores (2001) estudaram atletas com média de 13 anos de idade. Os resultados indicaram altos níveis de participação dos pais desde a fase inicial, o apoio tanto social quanto moral e econômico, sendo que esses achados corroboraram com a literatura internacional (Côté, 1999, Davidson \& cols., 1996).

Moraes e colaboradores (2001) estudaram atletas de voleibol juvenil de ambos os gêneros, com idades entre 16 e 19 anos, pertencentes às seleções goianas. Os resultados mostraram que os atletas tiveram a oportunidade de outras vivências esportivas antes de se definirem para o voleibol. Esses atletas contaram com o apoio dos pais durante seus anos iniciais, sem restrições financeiras ou motivacionais, semelhantes aos estudos de Salmela e colaboradores (2000). Os pais, na terceira fase de desenvolvimento dos atletas, passaram a cobrar de seus filhos um maior compromisso nos estudos, sugerindo uma mudança para outra carreira, devido à falta de estrutura dos clubes.
O futebol é para os brasileiros, sem dúvida, mais do que um esporte: é uma paixão que faz parte da sua cultura. Esse esporte vem sendo praticado nas mais variadas formas, em todos os locais possíveis e imagináveis, por pessoas de todas as classes e, recentemente, por atletas do gênero feminino no nível internacional. Salmela e Moraes (2003) deram uma contribuição sobre o tema, descrevendo o papel específico do futebol para a cultura brasileira e os papéis que, tanto o treinador quanto os pais, representam nesse esporte ao longo dos estágios de desenvolvimento de suas carreiras. Os autores verificaram também os estágios de desenvolvimento dos atletas de diferentes esportes da classe média, verificando que havia semelhanças com relação aos modelos de desenvolvimento na América do Norte e Europa (Bloom, 1985). Em contraste, as características de desenvolvimento de atletas no futebol brasileiro diferem das dos modelos americanos e europeus, pelo fato desse esporte envolver uma grande massa de participantes oriundos de classes sociais de baixa renda.

Considerando que o futebol é um esporte de extrema importância no Brasil, é surpreendente a escassa literatura abordando uma perspectiva psicológica nesse esporte. $\mathrm{O}$ fato sugere um melhor entendimento da rota do sucesso desses jovens jogadores de futebol, especialmente sobre as nuanças relacionadas à extensão que o papel da família pode ter no contexto do desenvolvimento de atletas nesse esporte (Salmela \& Moraes, 2003).

Portanto, o objetivo do presente estudo foi analisar o papel dos pais em relação aos seus níveis de envolvimento, em vários estágios do desenvolvimento atlético de seus filhos adolescentes, em diferentes equipes de futebol.

\section{Método}

Para o estudo da participação dos pais nesta pesquisa, optouseporutilizaruma abordagem tanto qualitativa quanto quantitativa. Este procedimento, segundo Miles e Huberman (1994), justifica-se na medida da possibilidade de: a) confirmação e corroboração, de uma abordagem com a outra, via triangulação; b) elaboração ou desenvolvimento de análises que proporcionem detalhes mais ricos; c) iniciação de novas linhas de pensamento através da atenção para surpresas ou paradoxos, despertando, para novas idéias. O procedimento de triangulação utilizado nesse estudo foi para acentuar a validade dos achados na pesquisa, que foi feita através de diferentes instrumentos de coleta fornecidos pelos pais e atletas.

\section{Participantes}

A pesquisa contou com a participação de 20 pais e respectivos 12 filhos/atletas de futebol. Os atletas deviam: a) ter entre $15 \mathrm{e}$ 
18 anos de idade; b) ter participado do campeonato mineiro na temporada de 2000 e alcançado uma das três primeiras colocações nessa disputa; c) ser reconhecidos pelos respectivos treinadores e suas comissões técnicas como atletas de destaque do clube e em condições de participar da pesquisa; d) obter autorização dos treinadores e pais para participar da pesquisa.

\section{Instrumentos}

Foram aplicados três diferentes instrumentos para a coleta de dados: a) formulário de respostas codificadas; b) questionário; c) entrevistas semi-estruturadas e de aprofundamento. $\mathrm{O}$ formulário de respostas codificadas foi o instrumento principal de coleta e discussão dos dados sobre a participação dos pais no desenvolvimento de seus filhos/atletas (Anexo A). As perguntas do formulário foram adaptadas de Davidson e colaboradores. (1996), o mesmo contém um grupo de questões que investigam a participação dos pais no desenvolvimento de seus filhos no futebol. Esse formulário consta de 11 questões, com 4 a 6 níveis de envolvimento, codificados e organizados de forma a representarem um continuum de envolvimento $(1=$ menor grau de envolvimento e $6=$ maior grau de envolvimento) dos pais nas atividades dos filhos. Essas questões foram agrupadas em quatro categorias: a) o envolvimento dos pais nos treinamentos formal e informal dos seus filhos (questões $1,2,3,4,6,9)$; b) a influência dos pais no futuro profissional dos filhos (questões 7,8 ); c) as mudanças na rotina familiar (questões 10,11); d) a vivência esportiva dos pais (questão 5).

Os outros instrumentos de coleta de dados, utilizados com o objetivo de acrescentar informações, complementando dados ao instrumento principal, foram: a) questionário utilizado com os pais para levantamento de dados objetivos: nome, idade, endereço, telefone, nível de escolaridade, estado civil, número de pessoas na casa, renda pessoal e familiar; e b) entrevistas semi-estruturadas e de aprofundamento, utilizadas com os pais e filhos/atletas participantes da pesquisa através de um guia geral de entrevistas que foi utilizado para auxiliar no momento da coleta de dados.

\section{Procedimentos de Coleta dos Dados}

A coleta de dados com os pais foi realizada em suas residências. Os pais responderam ao questionário e, em seguida, participaram das entrevistas, conduzidas por um pesquisador com intuito de diminuir as discrepâncias entre pesquisadores. Todas as entrevistas tiveram, em média, 30 minutos de duração e foram gravadas e filmadas, garantindose assim um back-up dos dados, caso fosse necessário recuperá-los. Após o final da entrevista, os pais responderam ao Formulário de Respostas Codificadas, que registrou a influência dos mesmos em três fases seqüenciais do desenvolvimento dos filhos no futebol (até os 7 anos, dos 8 aos 12 anos e dos 13 aos 18 anos), de acordo com o modelo de Bloom (1985).

Os filhos/atletas participaram das entrevistas semi-estruturadas e de aprofundamento conduzidas pelos pesquisadores. As entrevistas foram realizadas no Laboratório de Psicologia do Esporte (LAPES) da Universidade Federal de Minas Gerais (UFMG), ou nos próprios clubes de origem dos atletas, e tiveram em média 30 minutos de duração.

\section{Procedimentos para a Análise dos Dados}

Para a análise dos resultados dos formulários de respostas codificadas, as 11 questões (Anexo A) foram apresentadas e discutidas dentro de quatro categorias: 1) o envolvimento dos pais nos treinamentos formal e informal dos filhos; 2) a influência dos pais no futuro profissional dos filhos; 3) a rotina familiar; 4) a vivência esportiva dos pais. Com o objetivo de determinar o envolvimento dos pais no desenvolvimento de seus filhos no futebol, foi calculada a freqüência de respostas dos níveis de envolvimento para cada uma das 11 questões do formulário de respostas codificadas, considerando as três fases estudadas, através de valores percentuais.

Utilizou-se o teste de Friedman ANOVA E Kendall's Concordance para verificar se houve alteração no envolvimento dos pais, entre as três fases estudadas, sobre o desenvolvimento dos filhos atletas. O teste de Wilcoxon Matched Pairs Test foi utilizado como análise post-hoc. Adotou-se o nível de significância de $p<0,05$.

Os questionários forneceram informações sobre a amostra e o relacionamento entre pais e atletas. Os dados foram analisados quantitativamente, descrevendo-se a freqüência das respostas, como também a média e desviopadrão obtidos. As entrevistas semi-estruturadas e de aprofundamento foram utilizadas como informações complementares, para reforçar a veracidade das respostas do formulário dos pais. Cada grupo de entrevistados recebeu um código, seguindo a seguinte ordem: atletas (A), mães (M) e pais $(\mathrm{P})$. Foi feita a análise das entrevistas, seguindo os procedimentos descritos por Côté, Salmela, Baria e Russell (1993). Segundo essa metodologia, a análise foi feita em três momentos principais: transcrição, organização dos dados em pequenas partes de informações, chamadas de meaning units (MU), que podem ser, por exemplo, a menor parte compreensível de um texto, parágrafo ou sentença, que contém uma idéia, episódio ou pedaço de informação, e interpretação dos dados.

\section{Resultados}

Questionário. Foi observado que os pais tinham os seguintes graus de instrução: um dos pais não tinha nenhuma instrução 
(5\%), 12 pais tinham até o primeiro grau completo $(60 \%)$, seis pais tinham até o segundo grau completo (30\%), e apenas um dos pais tinha o terceiro grau (5\%). Os resultados indicaram ainda que os pais tinham em média 50 anos de idade, a renda familiar mensal média era de $\mathrm{R} \$ 500,00$ e que as familias eram compostas, em geral, de 4 pessoas. As familias avaliadas residem em quatro estados, sendo a maioria no estado de Minas Gerais, porém, fora da cidade de Belo Horizonte, que ficam entre 120 e $250 \mathrm{~km}$ de distância da capital.

Formulário de respostas codificadas entrevistas semi-estruturadas. Não foram apresentadas diferenças estatísticas significativas sobre o envolvimento dos pais nas atividades de seus filhos, entre $1^{a}$ e $2^{a}$ fases de desenvolvimento. Todavia, os resultados demonstraram que houve diferenças significativas no comportamento dos pais na 3 fase, quando comparada às outras duas. As fases e questões serão apresentadas dentro das 4 categorias.

\section{Envolvimento dos Pais no Treinamento Formal e Informal dos Filhos no Futebol}

Presença dos pais nas aulas dos filhos. Os resultados demonstraram que houve um grupo de pais com falta de envolvimento nas aulas dos filhos. Durante as duas primeiras fases, 60\% (12 pais) tinham pouquíssimo envolvimento nas aulas do filho, sendo este, o nível de mais baixo envolvimento (Anexo A). Durante a terceira fase, o percentual, no nível de menor envolvimento, aumentou significativamente $(F(2,20)=11,545$; $p<, 003)$ para $90 \%$, demonstrando um aumento da falta de envolvimento dos pais nas aulas dos filhos ao longo do tempo. As narrativas a seguir ilustram os resultados encontrados:

porque hoje eu vejo, até me arrependo sinceramente, hoje eu vejo as mães que botam [os filhos] nas escolinhas [de futebol], vejo as mães levando os meninos todos arrumadinhos e falo assim: pois é e olhe só , levei um tapa de luva, né, não dei apoio a meu filho, e o meu filho, onde chegou. (M10)

Não ia aos treino dele não. Os treino dele, era difícil eu sair de casa, para te falar a verdade. Eu tinha que arrumar, assim, um tempo para mim sair. Agora que eu tô tendo um tempinho. Mas era levantar e até à noite trabalhando. Então num acompanhava o treino dele, não. ( M4)

Atuação dos pais motivando os filhos para o treinamento. Os pais não atuaram de forma a motivar seus filhos para o treinamento, pois consideravam que eles eram inteiramente motivados. Como houve uma pequena variação no comportamento dos pais nas três fases, não foi possível e nem necessária a utilização de cálculos estatísticos. Os pais também confirmaram nas entrevistas que seus filhos eram inteiramente motivados para o treinamento:

Isso aí num precisa mandar não. Ele faz mesmo, faz e gosta de bola,... foi lá para jogar um pouquinho com eles, para falar que ele não foi, né. Mas ele também gosta de ir, mas nunca precisou de mandar ele ir fazer a física, treinar, e sempre isso aí ele faz por ele mesmo. ( P5)

Não, de jeito nenhum, não precisava nem falar pra ele, ele já estava lá, era o primeiro do treino, até hoje é assim, lá no clube. Até o cara lá tava falando pra mim, o treinador do time. O presidente falou "Esse rapazinho é muito boa pessoa, num precisa chamar não, falou que tem treino já tá lá, montadinho já para a partida. (P10)

Participação dospais nas atividades esportivas dos filhos. A questão revelou, em termos de presença, uma ausência de participação dos pais nas atividades esportivas do filho. Todavia, durante as três fases estudadas, $65 \%$, 70\% e 75\% dos pais, respectivamente, declararam que perguntavam sobre as atividades esportivas do filho. O comportamento dos pais não foi diferente estatisticamente ao longo do tempo $\{F(2,20)=3,000, p<0,223\}$. As entrevistas demonstraram que o envolvimento dos pais acontecia através de conversas, o que confirma os resultados:

A única coisa que a gente faz hoje, é que a gente conversa muito, porque ele já teve uma época, depois que ele estava em B.H; teve [um] colega dele que desistiu, e ele [filho] telefonava pra mim e falava: Ah mãe, eu vou embora , num vai dar mais. E eu sempre falava com ele: Você escolheu esse caminho, se é isso que você quer, cê vai ter que ter paciência de agüentar. (M3)

Presença dos pais nas competiçoes dos filhos. Os pais demonstraram-se envolvidos com as competições dos filhos. Durante a primeira e segunda fase de desenvolvimento, $45 \%$ e $50 \%$ dos pais compareciam regularmente às competições dos filhos até os 12 anos de idade, sendo esse o nível de mais alto grau de participação. Durante a terceira fase, $75 \%$ dos pais passaram a ver as competições regularmente pela TV, "Assistíamos aos jogos, eu ia ver ele jogar, desde do infanto. Do infanto eu já comecei a assistir os jogo dele". (P10), o que representa uma mudança significativa no que se refere à participação nos jogos, mas parecendo que o envolvimento continuava, através da TV, jornais e telefonemas, mesmo sem estarem presentes com o passar do tempo $(F(2,20)=6,421 ; p<0,040)$. As entrevistas confirmaram o envolvimento dos pais com o esporte dos filhos, conforme demonstra a MU seguinte: 
Não, eu levava, quando ele era muito pequenininho, eu levava; depois ele passou a crescer um pouquinho, já ia sozinho, mas todo futebol que ele jogava eu ia acompanhar causa da distância fica difícil, só mesmo quando tiver na televisão para gente. (M7)

Envohimento dos pais na orientacão do treinamento dos filhos. A freqüência de respostas dos pais, 55\%, 55\% e 60\%, durante as três fases, respectivamente, demonstra que a maioria dos pais não tiveram nenhum envolvimento (nível de envolvimento 1 - Anexo A) na orientação do treinamento dos filhos, eque não houve mudança significativa de comportamento em relação ao tempo, $(F(2,20)=2,000 ; p<0,367)$. Todavia, 35\% dos pais declararam que, como ex-atletas, passavam orientações para os filhos, durante as três fases de desenvolvimento, indicando um bom envolvimento desses pais. As entrevistas apresentaram resultados semelhantes, endossando as respostas representadas nas MUs:

Justamente, ele me cobrou pra fazer isso, pra mim treinar ele, e pra ... eu ter o time. Eu falei: esse negócio não dá certo, de mexer com menino, não. Eu tenho paciência com os velhos, com os grandes, os velhos conseguem me compreender, e eu estou preparado pra os grandes; para os pequenos quem está preparado é o seu treinador. (P12)

Eu, sinceramente, pouco conversava com o treinador dele, mas todas as vezes que eu conversava com o treinador: "Olha o seu menino é bom, ele tá desenvolvendo bem, e tal, tal”; e eu nunca tive proximidade do treinador, assim de chegar, de perguntar, de cobrar, entendeu, nunca fui corujão. (P2)

De vez em quando eu ia assistir meu pai. Não sabia que tinha futebol direito, não sabia se ia ter aula. Depois eu fui pegando as coisas. Ele é calmo até demais. Dá instrução, aconselha que jogador não deve beber, fumar porque prejudica bastante. Mas ele é um cara calmo, ajuda bastante. É um grande pai.(A3)

Atividades extras diárias relacionadas ao futebol. Os resultados nesta questão demonstraram o nível de envolvimento dos pais em relação às atividades extras diárias dos filhos, relacionadas ao futebol. Nas duas primeiras fases, $85 \%$ dos pais, e $80 \%$ na terceira fase declararam que os filhos dedicavam o tempo livre a atividades com bola, não apresentando diferenças estatisticamente significativas $(F(2,20)=2,000 ; p<0,367)$. Sendo assim, essa pergunta evidencia que, apesar dos filhos, com o passar do tempo, estarem treinando em clubes e lidarem com o futebol de uma maneira profissional, continuaram praticando o futebol em seu tempo de lazer. Abaixo, alguns exemplos dos pais ao falarem sobre o horário de lazer dos filhos:

Ele nunca deixou de ir na escola, faltar de aula para jogar bola, não, mas se ele chegasse do treino, se ele viesse para dentro e algum amigo dele chegava e chamava ele, ele ficava na rua jogando até tarde, na rua mesmo, qualquer lugar era lugar para ele jogar bola. (M8)

Acabava o treino e entrava aqui na quadra de futebol de salão, parava não, ele toda vida gostou de bola. Nessa época jogava o dia inteiro, fominha mesmo, a turma falava assim: Esse aí vai ter que ser profissional. (P10)

\section{Influência dos Pais no Futuro Profissional dos Filhos}

Interferência dos pais na escollha da carreira profissional dos filhos. A implicação dos pais na escolha profissional dos atletas foi moderada, sendo que $55 \%$ dos pais não davam opinião sobre a escolha profissional dos atletas durante as duas primeiras fases e $65 \%$ durante a terceira fase. As três fases não foram diferentes estatisticamente $(F(2,20)=2000 ; p<0,367)$. As entrevistas com os pais confirmaram os resultados, como demonstra a MU:

Não... não estive conversando não. Isso aí, toda vida, ele nunca falou. O plano dele, toda vida, é bola mesmo, nunca se tocou em outra carreira. Até para estudar, agora, ele já parou, ele não é muito chegado no estudo, não. Ele estuda é meio obrigado. O negócio dele é bola. (P5)

Cobrança do estudo em relação ao esporte. Para os pais, o estudo era um fator importante no desenvolvimento de seus filhos, apresentando uma preocupação não só com o esporte, mas com a melhoria do nível de instrução. Durante as duas primeiras fases, $65 \%$ dos pais cobravam dos filhos desempenho nos estudos e no esporte. Esse comportamento se manteve durante a terceira fase, aumentando a freqüência de respostas para $70 \%$, o que não foi estatisticamente significativo $(F(2,20)=2000 ; p<$ $0,367)$. Essa tendência também ficou demonstrada nas entrevistas com os pais:

Pois é, aí esse lado sempre foi cobrado mesmo, que são duas coisas para serem trabalhadas juntas. Isso eu falava para ele: Nem você pode soltar um nem o outro, é o estudar e o futebol. Você gosta de futebol, cê vai dedicar ao futebol. A escola, você vai dedicar à escola, são duas coisas. E falei para ele: nessa vida, dá para fazer várias coisas ao mesmo tempo, né. (M6) 
Eu, igual eu falei com ele: Você quer jogar futebol, então tem que agarrar as duas coisas, você tem que garrar nos livros e na bola, porque eu não vou abrir mão do colégio não. Aí ele estudou aqui até a sexta série, aí depois da sexta série ele foi pra Belo Horizonte, aí lá ele estudou até a oitava. (M3)

Não tinha cobrança não, mas eu acho que é um erro, porque, como diz o outro, se a pessoa pratica um esporte, ela também tem que estudar, porque sem o estudo, também não vai adiantar muita coisa não. Então eu acho que mesmo praticando esporte, mesmo indo bem no esporte, no estudo também tem que ir bem. (P2)

\section{Mudanças na Rotina Familiar}

Mudança na rotina dos pais em função da prática esportiva dos filhos. A maioria dos pais não mudou suas rotinas em função da prática esportiva do filho, indicando, porém, um pequeno envolvimento. Durante as duas primeiras fases, $85 \%$ dos pais não tiveram nenhuma alteração em suas rotinas, assim como $80 \%$ durante a terceira fase, "Não, nada assim que mudasse muito não. É só em relação ao tempo, mas dava pra gente encaixar, ou ele esperava um pouco ou eu esperava um pouco, a gente organizava". (M6). Esses resultados não foram estatisticamente diferentes nas três fases $(F(2,20)=0,666 ; p<0,716)$. Estas narrativas confirmam as respostas dos pais sobre as mudanças de rotina em função do futebol dos filhos:

Eu mesma num mudei não, mas quase que eu mudo, chegou ao ponto da gente falá: Nós vão ter que ir embora, porque ninguém estava conseguindo ficar sem ele aqui. É muito novo, minha preocupação era demais, Nossa Senhora, foi duro, mas depois a gente foi acostumando. (M12)

Frequiência com que se encontravam com seus filhos. A freqüência com que os pais se encontravam com os filhos passou do nível de maior para o de menor envolvimento. Nessa questão houve alteração significativa no comportamento dos pais $(F(2,20)=38,838 ; p<, 000)$. Na $1^{a}$ e $2^{a}$ fases, $95 \%$ e $85 \%$ dos pais, respectivamente, tinham contato diário com seus filhos, sendo que, durante a terceira fase, $90 \%$ dos pais se encontravam com seus filhos apenas a cada três meses. Isso revela que a quantidade do apoio familiar decresceu, "Quando ele foi pra lá, de duas em duas semanas ele estava na casa da gente. Agora é de 2 em 2 meses, 3 meses, até 4 meses sem vir. É difícil. Então nós fala com ele pelo telefone". (P7). Esse comportamento se deu, principalmente, pela mudança dos atletas para Belo Horizonte, já que as familias não puderam acompanhá-los.

\section{Vivência Esportiva dos Pais}

Envolvimento dos pais com o esporte. A freqüência de respostas dos pais demonstrou que 50\% (10 pais) não teve nenhum envolvimento com esportes como praticantes, "Não, de jeito nenhum. No meu tempo não havia isso aí, eu nunca pratiquei esporte nenhum" (P1), 10\% (2 pais) o tiveram quando crianças, mas interromperam, e 10\% (2 pais) praticam alguma atividade ocasionalmente. Entretanto, $20 \%$ (4 pais) jogam como amadores regularmente e 10\% ( 2 pais) foram atletas profissionais ou de alto nível, "Eu mesmo procurei. Mas meu pai já foi profissional também. Foi jogador de futebol. Filho de peixe peixinho é. Aí eu acabei dando certo" (A3). Esses resultados percentuais indicam que a maioria dos atletas participantes deste estudo não teve os pais como modelos do esporte.

\section{Discussão}

Esses resultados iniciais diferem de Yang e colaboradores (1996), que afirmam que o nível sócio-econômico e educacional dos pais não influencia a participação em atividades esportivas dos filhos. Contudo, esta pesquisa foi feita em um contexto muito diferente do norte-americano, o que indica a necessidade de novas investigações nessa área para um melhor entendimento do assunto.

Os resultados do questionário mostraram que a maioria dos pais tem um baixo grau de escolaridade, assim como pequeno poder aquisitivo, pois a renda familiar, em média, é menor do que um salário mínimo por pessoa. O baixo poder aquisitivo pode ter representado uma restrição para os pais oferecerem apoio aos seus filhos, pelo custo inerente a transporte, material, aulas, incluindo as práticas de diferentes esportes. Todavia, a liberdade permitida pelos pais para a prática do futebol, a não cobrança de contribuição para o sustento da casa, a paixão dos filhos pelo futebol e facilidade contextual para a prática; ajudaram no seu desenvolvimento profissional no futuro (Salmela \& Moraes, 2003).

Outro dado que chama a atenção é que essas famílias não moram em Belo Horizonte, sendo, na sua grande maioria, provenientes de cidades do interior. Essa situação indica uma incapacidade de participação dos pais junto a seus filhos e treinadores após a vinda para o clube, na $3^{a}$ fase de desenvolvimento. Isso torna difícil uma atuação consistente dos pais, nas diversas atividades dos filhos no esporte, especialmente na $3^{a}$ fase, que é descrita como um fator importante para alcançar altos níveis de performance no futuro. $\mathrm{O}$ envolvimento dos pais no treinamento formal e 
informal dos filhos demonstrou que eles não motivavam seus filhos para o treinamento no futebol, eram pouco envolvidos nas aulas, com a orientação do treinamento, assim como com as práticas esportivas. Talvez isso tenha ocorrido, como citado anteriormente, pelo fato de os pais terem uma baixa renda e não poderem acompanhar de perto os seus filhos (Jambor, 1999).

Segundo Bloom (1985) e Côté (1999), os pais, durante a carreira de seus filhos, são responsáveis por acompanhálos, encorajando-os, ajudando-os na prática diária e enfatizando o valor desta, o que parece não ter acontecido totalmente no presente estudo. Ainda, a participação dos pais seria de grande importância para minimizar as restrições de esforço e as restrições de motivação. Todavia, neste estudo, os pais acreditavam que não era necessário motivarem seus filhos para a prática, porque estes eram intrinsecamente motivados. Quanto à ajuda dos pais para minimizar o esforço dos filhos, pode-se inferir que, como esses não acompanhavam de perto os filhos, provavelmente não ajudavam também neste quesito.

A participação dos pais no estabelecimento de metas e no cumprimento de tarefas (Carr \& cols., 2000) são questões importantes para que os filhos alcancem resultados na carreira. No presente estudo com pais de jovens futebolistas, a maioria não participava das atividades, não acompanhava as aulas e treinamentos de seus filhos, todavia, contribuíram parcialmente no estabelecimento de metas para a melhoria da performance, como também na ajuda no cumprimento das tarefas. Esses pais, apesar da ausência em diferentes momentos da vida dos jogadores, estabeleceram a condição de que os mesmos somente poderiam jogar futebol se estudassem.

Segundo Davidson e colaboradores (1996), o sucesso na aquisição de habilidades na música está relacionado com um alto grau de participação dos pais, o que não aconteceu neste estudo com o futebol. Uma explicação para esse não comprometimento, poderia ser a de que as crianças encontram no futebol um grande prazer, podendo praticar durante longo tempo mesmo sem o acompanhamento dos pais (o que não acontece na música). Por exemplo, para aprenderem música, as crianças, sob a assistência dos pais, tinham que praticar em casa os exercícios prescritos pelo professor (Salmela \& Moraes, 2003).

Entretanto, pôde-se observar que, apesar de a maioria dos pais indicar pouca participação nas atividades dos filhos, houve também um certo envolvimento deles quanto ao retorno de informação do professor e a orientação para o treinamento. Porém, ocorreu que as mães, que foram maioria neste estudo, não praticam futebol, e provavelmente, não conhecem bem esse esporte, pouco se envolvendo com essas questões. Isso pode ter desviado a freqüência de comportamento para níveis de baixo envolvimento, ficando a participação reduzida apenas aos pais, que praticaram futebol e entendem suas regras.

Em estudo realizado no Brasil por Moraes e colaboradores (2001), com atletas de voleibol, e Vianna Júnior e colaboradores (2001), com a ginástica rítmica desportiva ou esporte da classe média, os autores verificaram que a participação dos pais foi de grande importância para o desenvolvimento dos filhos, corroborando a literatura internacional sobre o assunto. Contudo, Moraes e colaboradores (2000) encontraram resultados diferentes aos desta pesquisa, ao estudarem atletas de futebol e o apoio dos pais para o desenvolvimento no esporte, verificando que, na visão dos atletas, a participação dos pais no desenvolvimento dos filhos no futebol era marginal.

O envolvimento dos pais nas competições dos filhos foi alto durante as duas primeiras fases estudadas, sendo que, com o passar do tempo, esse envolvimento decresceu. A aparente razão para tal fato está na mudança dos filhos para Belo Horizonte, ficando dificultada a participação dos pais. Mesmo assim deve-se acrescentar o apoio dos pais através de acompanhamento pela televisão. Conversas e perguntas pelo telefone também foram contribuíram para incentivar os atletas em suas carreiras no futebol, especialmente quando estavam distantes da família. Esse comportamento não encontra apoio na literatura sobre o desenvolvimento do expert (Bloom, 1985; Côté, 1999; Davidson \& cols., 1996). O comparecimento dos pais, apenas nas competições, poderia ser interpretado pelos filhos como um fator de pressão, que, segundo Hellstedt (1990), em altos níveis seria prejudicial. Em níveis adequados, porém, promove reações positivas, o que parece ter ocorrido.

Com relação às atividades extras diárias, relacionadas ao futebol, houve um alto nível de dedicação dos atletas durante todas as fases estudadas. Mesmo com o passar do tempo, os filhos tinham o futebol como a principal atividade de lazer, apesar de serem contratados pelos clubes profissionais. Esse comportamento deveria ter sofrido alterações, com a diminuição da participação do tempo livre com o futebol. Os estudos sobre atletas demonstram que o prazer é importante no seu desenvolvimento, porém, o tempo livre que possibilita a 
busca desse prazer vai sendo dedicado a outras atividades no decorrer das diferentes fases, como um descanso para o praticante (Carlsson, 1993). Entretanto, isso não ocorreu no presente estudo, reforçando a idéia da paixão que o brasileiro tem pelo futebol (Salmela \& Moraes, 2003).

Nesse mesmo sentido, Côté (1999) afirma que, durante o início do desenvolvimento, a prática acontece na forma de brincadeira e, com o passar do tempo, esse tipo de prática vai diminuindo à medida que aumenta a intensidade do treinamento. Todavia, essa redução apresentada pelos autores não ocorreu nesse estudo, por causa da paixão pelo jogo, como também pela busca financeira, o que pode ter sido determinante para que o desenvolvimento dos filhos independesse de apoio dos pais (Ladewig, Martins, Campos, Cuthma \& Gallagher, 2000).

O prazer dos filhos na prática esportiva tem alta relação com o envolvimento dos pais, o que, segundo Ommundsen e Vaglum (1991), no futebol, parece estar relacionado também ao comportamento e às interações emocionais. $\mathrm{Na}$ presente pesquisa com os pais, apesar de estes não motivarem seus filhos, não assistirem aos treinos e não darem orientações para o treinamento, a sua participação nas competições na $1^{\mathrm{a}}$ e $2^{\mathrm{a}}$ fases pode ter sido considerada pelos filhos como suficiente emocionalmente para influenciar o prazer pela prática do futebol.

A maioria dos pais não interferiu na escolha da carreira profissional dos filhos, o que demonstrou pouco envolvimento, segundo a freqüência de respostas apresentadas. Os demais pais dividiram-se em dois grupos equivalentes: os que apoiavam as carreiras ligadas ao futebol e os que sugeriam outras profissões. Esses resultados indicam uma falta de interferência dos pais. Com relação aos estudos, os pais, em sua maioria, cobravam desempenho tanto nos estudos como no futebol. Essa cobrança pode ter contribuído para que os filhos, indiretamente, entendessem a importância de metas e cumprimento de tarefas, que são relevantes no desenvolvimento no esporte (Carr \& cols., 2000; Côté, 1999).

A atitude dos pais, quanto aos estudos, parece estar também ligada à preocupação com o futuro dos filhos, caso não fossem bem-sucedidos no esporte (Jambor, 1999). Atingir o alto nível no esporte leva tempo e, durante o percurso, muitos percalços podem acontecer na carreira do jogador, como uma contusão. A instrução dos filhos, de certa forma, garantiria uma melhor condição de vida, caso houvesse uma interrupção repentina em sua carreira no futebol (Van Yperen, 1998).

Os pais não alteravam suas rotinas em função da prática dos filhos no futebol. Nesse quesito, os resultados demonstraram pouco envolvimento deles com relação à mudança de rotina. A não alteração das rotinas dos pais parece estar ligada às facilidades encontradas pelos filhos para jogar futebol e comparecer aos treinos em suas cidades, considerando que as cidades do interior são pequenas e não apresentam grandes riscos. Outra explicação já evocada é a necessidade de os pais terem que sobreviver com baixas rendas e não poderem sustentar os filhos no esporte (Salmela \& Moraes, 2003). Outro ponto de vista para explicar o sucesso desses atletas, apesar do pouco envolvimento dos pais pode ser a liberdade que tiveram para procurar o próprio sucesso. Comparados com os pais pesquisados por Côté (1999) nos esportes e Davidson e colaboradores (1996) na música, a liberdade que os pais brasileiros davam para os atletas jogarem, possivelmente foi uma alternativa que deu resultado mesmo não envolvendo intensivamente nas atividades diárias dos filhos como eram os pais norteamericanos.

Quanto ao contato dos pais com os filhos, uma presença mais próxima poderia influenciar o comportamento dos filhos (Bloom, 1985; Côté, 1999; Davidson \& cols., 1996). Esse contato, que era diário nas duas primeiras fases estudadas, passou para trimestral na última. A principal razão para a alteração de comportamento foi a mudança dos filhos para Belo Horizonte. Devido aos custos e às implicações para todos os membros da família, esta não acompanhou o filho em sua mudança. Esse tipo de envolvimento difere dos apresentados por Bloom (1985) e Côté (1999) para o desenvolvimento de atletas e de Ciskszentmihalyi e colaboradores (1993), sobre a noção de complexo familiar, os quais afirmam que os pais chegavam a mudar de cidade para acompanhar os filhos.

No Brasil, os estudos de Moraes e colaboradores. (2001) no voleibol, e Vianna Júnior e colaboradores (2001) na ginástica rítmica desportiva, apontam para a mesma direção encontrada nos estudos internacionais. No futebol, porém, esses resultados não foram semelhantes (Moraes \& cols., 2000), nos quais os pais não acompanhavam o progresso de seus filhos através de uma contribuição marcada pela presença.

Ainda de acordo com Wylleman, Knopp, Ewing e Cummung (2000) e Salmela e colaboradores (2000), o 
acompanhamento dos pais durante as transições na carreira proporciona condições para que os filhos possam avançar de forma consistente e constante, contribuindo para a interação entre pais, filhos e treinadores. Os resultados desta pesquisa demonstraram uma ausência de acompanhamento dos pais, principalmente depois dos filhos se mudarem para outra cidade, podendo, dessa forma, em momentos críticos, prejudicar a sua performance segundo os achados de Van Yperen (1998). Os resultados, de maneira geral, comparados com os de Hellstedt (1990), indicaram que houve um subenvolvimento dos pais no desenvolvimento de seus filhos no futebol, e que os pais não tiveram um crescente envolvimento, à medida que os filhos melhoravam em suas performances. Essa classificação indica que os resultados foram opostos aos de Côté (1999) e Davidson e colaboradores (1996). Todavia, deve ser registrado que a realidade contextual brasileira sugere que, algumas atitudes dos pais dos atletas tiveram que ser adaptadas, por diferentes razões, inclusive a financeira, mas que demonstraram um envolvimento, mesmo longe dos atletas. Esse é o caso de alguns pais permitindo aos seus filhos a prática total do futebol como prioridade principal de suas vidas.

A diminuição da participação dos pais, com o passar do tempo, é esperada (Bloom, 1985), porém, neste presente estudo essas alterações parecem ter acontecido muito cedo, demonstrando uma certa precocidade nas mudanças dos diferentes tipos de envolvimento dos pais. Apesar da ausência dos pais colaborar para o enfraquecimento do apoio, o desenvolvimento dos filhos não parece ter sido comprometido. $\mathrm{Na}$ verdade, a motivação dos filhos para mudar e continuar jogando futebol longe da família era para que pudessem, um dia, oferecer melhores condições de vida aos seus pais.

A maior parte dos pais não teve envolvimento com a prática esportiva, sendo que alguns deles praticavam ou ainda praticam esporte. Provavelmente, isso aconteceu por causa do nível econômico das famílias. Segundo Bloom (1985), os pais servem de exemplo para os seus filhos nos anos iniciais, nas diversas áreas do conhecimento. Yang e colaboradores (1996) também ressaltam sobre os pais que praticam esportes, influenciando o ingresso dos filhos na prática esportiva. Entretanto, os pais não parecem ter sido praticantes exemplares nesta investigação, apesar de Jambor (1999) acreditar que, no futebol, os pais podem atuar como responsáveis pela introdução de seus filhos no esporte, mesmo que não o pratiquem. As razões podem ser variadas, como por exemplo, a paixão dos pais pelo futebol. Assim sendo, é grande a possibilidade de tios, irmãos, amigos, entre outros, terem desempenhado também esse papel, influenciando os iniciantes no futebol (Carlsson, 1993). Outra razão, não menos importante para o início da prática do futebol pelos filhos, é o apelo financeiro deste esporte, no qual jogadores podem ganhar muito dinheiro. Isso propicia uma melhoria econômica de vida, uma vez que a maioria desses atletas vem de famílias de baixo poder aquisitivo.

\section{Conclusão}

Parece evidente que o desenvolvimento expoente de atletas do futebol brasileiro e o papel dos pais nesse processo de envolvimento desafiam os modelos conceituais e as pesquisas sobre as carreiras de esportistas em países desenvolvidos, apresentados por diferentes autores. Isso pode ser mais um reflexo do status sócio-econômico do que qualquer outro, particularmente para o Brasil. Nesse sentido, está claro que a performance expoente do futebol brasileiro ocorre em diferente simetria se, comparado com a literatura internacional sobre o assunto. Todavia, deve-se entender que a relativa falta de apoio dos pais não impediu o sucesso desses futebolistas, evidenciando que esse papel, único do futebol na cultura brasileira, ultrapassa as restrições de apoio dos pais ou até mesmo a qualidade de orientação técnica.

\section{Referências}

Bloom, B. S. (1985). Developing talent in young people. New York: Ballantine.

Carlsson, R. (1993). The path to the national level in sports in Sweden. Scandinavian Journal of Medicine and Science Sports, 3, 170-177.

Carr, S., Weigand, D. \& Jones, J. (2000). The relative influence of parents, peers, and sporting heroes on goal orientations of children and adolescents in sport. Journal of Sport Pedagogy, 6, 34-55.

Côté, J. (1999). The influence of the family in the development of talent in sport. The Sport Psychologist, 13, 395-417.

Côté, J., Salmela, J. H., Baria, A. \& Russell, S. J. (1993). Organizing and interpreting unstructured qualitative data. The Sport Psychologist, 7, 127-137.

Csikszentmihalyi, M., Rathunde, K. \& Whalen, S. (1993). Talented teenagers: The roots of success and failure. Toronto: Cambridge University Press.

Davidson, J. W., Howe, M. J., A. Moore, D. G. \& Sloboda, J. A. (1996). The role of parental influences in the developmental of musical performance. British Journal of Developmental Psychology, 14, 399-442.

Durand-Bush, N. \& Salmela, J. H. (2002). The development and maintenance of expert athletic performance: Perceptions of World and Olympic champions. Journal of Applied Sport Psychology, 14, 154-171.

Hellstedt, J. C. (1990). Early adolescent perceptions of parental pressure in the sport environment. Journal of Sport Behavior, 13, 135-144.

Jambor, E. A. (1999). Parents as children's socializing agents in youth soccer. Journal of Sport Behavior, 22, 350-357. 
Ladewig, I., Martins, D. F., Campos, W., Cuthma, C. R. \& Gallagher, J. D. (2000). Cultural influences on the development of soccer knowledge base of Brazilian females. Journal of Sport and Exercise Psychology, 22, S 64.

Miles, M. B. \& Huberman, A. M. (1994). Qualitative data analysis $\left(2^{\text {nd }}\right.$.ed.). Thousand Oaks, CA: Sage.

Moraes, L. C., Salmela, J. H., Rabelo, A. S. \& Vianna Júnior, N. S. (2000). The development of exceptional performance of young brazilian soccer players [Resumo]. Em AAASP Conference Proceedings (p. 41). Nashville, TN.

Moraes, L. C., Salmela, J. H., Rabelo, A. S., Lima, M. S. O. \& Lôbo, I. L. B. (2001). Desenvolvimento de jovens atletas de voleibol [Resumo]. Em D. Samulski (Org.), Anais de V Congresso Mineiro de Psicologia do Esporte (p 23). Belo Horizonte: CENESP.

Ommundsen, Y. \& Vaglum, P. (1991). Soccer competition anxiety and enjoyment in young boy players: The influence of perceived competence and significant others' emotional involvement. International Journal of Sport Psychology, 22, 35-49.

Salmela, J. H., Young, B. W. \& Kallio, J. (2000). Within-career transitions of the athlete-coach-parent triad. Em D. Lavallee \& P. Wylleman (Orgs.), Career transitions in sport: International perspectives (pp. 181-193). Morgantown, WV: FIT.

Salmela, J. H. \& Moraes, L. C. (2003). Coaching expertise, families and cultural contexts. Em L. Starkes \& K. A. Ericsson (Orgs.), Expert performance in sport: Advances in research on sport expertise (pp. 275-296). Champaign, IL: Human Kinetics.
Van Yperen, N. W. (1998). Interpersonal stress, performance level, and parental support: A longitudinal study among highly skilled young soccer players. The Sport Psychologist, 9, 225-241.

Vianna Júnior, N. S., Moraes, L. C., Salmela, J. H. \& Mourthé, K. (2001). The role of parents in the development of young Brazilian athletes in rhythmic gymnastics [Resumo]. Em AAASP Conference Proceedings (p. 61). Orlando, FL: Ronjon,

Wylleman, P., Knopp, P., Ewing, M. E. \& Cummung, S. P. (2000). Transitions in youth sport: A developmental perspective on parental involvement. Em D. Lavallee \& P. Wylleman (Orgs.), Careertransitions in sport: Internationalperspectives (pp. 143-160). Morgantown, WV: FIT.

Yang, X., Telema, R. \& Laakso, L. (1996). Parent's physical activity socieconomic status and education as predictors of physical activity and sport among children and youths: A 12-year follow-up study. International Review for Sociology of Sport, 31, 273-294.

\section{Sobre os autores}

Luiz Carlos Moraes é Professor Adjunto da Universidade Federal de Minas Gerais. É Mestre pela Michigan State University, em Michigan, EUA, e Doutor pela University of Ottawa, no Canadá.

André Scotti Rabelo é Professor da Associação de Ensino Versales, Minas Gerais. É Mestre pela Universidade Federal de Minas Gerais.

John Henry Salmela é Professor visitante da Universidade Federal de Minas Gerais. É Mestre pela University of Western Ontario e Doutor pela University of Alberta, no Canadá. 
Anexo A

Tabela 1

Formulário de Respostas Codificadas

\begin{tabular}{|c|c|c|c|c|c|c|c|}
\hline \multicolumn{2}{|c|}{ Questões } & \multicolumn{6}{|c|}{ Nível de Envolvimento } \\
\hline & & 1 & 2 & 3 & 4 & 5 & 6 \\
\hline 1 & $\begin{array}{l}\text { Envolvimento dos } \\
\text { pais nas aulas do filho }\end{array}$ & $\begin{array}{l}\text { Nenhum } \\
\text { envolvimento } \\
\text { nas aulas }\end{array}$ & $\begin{array}{l}\text { Providenciava } \\
\text { transporte para } \\
\text { as aulas }\end{array}$ & $\begin{array}{l}\text { Recebia retorno } \\
\text { regularmente do } \\
\text { professor }\end{array}$ & $\begin{array}{l}\text { Estava presente } \\
\text { às aulas }\end{array}$ & & \\
\hline 2 & $\begin{array}{l}\text { Atuação dos pais na } \\
\text { motivação do filho } \\
\text { para o treinamento }\end{array}$ & $\begin{array}{l}\text { Criança } \\
\text { inteiramente } \\
\text { motivada }\end{array}$ & $\begin{array}{l}\text { Motivada, mas } \\
\text { necessitava } \\
\text { encorajamento } \\
\text { dos pais }\end{array}$ & $\begin{array}{l}\text { Precisava de } \\
\text { considerável } \\
\text { encorajamento } \\
\text { dos pais }\end{array}$ & $\begin{array}{l}\text { Não treinava } \\
\text { sem a insistência } \\
\text { dos pais }\end{array}$ & & \\
\hline 3 & $\begin{array}{l}\text { Participação dos pais } \\
\text { nas atividades } \\
\text { esportivas do filho }\end{array}$ & $\begin{array}{l}\text { Nenhuma } \\
\text { participação }\end{array}$ & $\begin{array}{l}\text { Perguntava } \\
\text { sobre as } \\
\text { atividades }\end{array}$ & $\begin{array}{l}\text { Oferece-se ou é } \\
\text { solicitado para as } \\
\text { atividades }\end{array}$ & $\begin{array}{l}\text { Propicia e } \\
\text { participa } \\
\text { ativamente das } \\
\text { atividades }\end{array}$ & & \\
\hline 4 & $\begin{array}{l}\text { Presença dos pais nas } \\
\text { competições do filho }\end{array}$ & Nunca assistia & $\begin{array}{l}\text { Assiste às } \\
\text { competições } \\
\text { ocasionalmente } \\
\text { na TV }\end{array}$ & $\begin{array}{l}\text { Assiste às } \\
\text { competições } \\
\text { regularmente } \\
\text { na TV }\end{array}$ & $\begin{array}{l}\text { Comparece à } \\
\text { competição } \\
\text { ocasionalmente } \\
1 \text { a } 4 \text { vezes/ano }\end{array}$ & $\begin{array}{l}\text { Comparece à } \\
\text { competição } \\
\text { regularmente } \\
+4 \text { vezes/ano }\end{array}$ & \\
\hline 5 & $\begin{array}{l}\text { Envolvimento dos } \\
\text { pais com esporte }\end{array}$ & $\begin{array}{l}\text { Nenhum } \\
\text { envolvimento }\end{array}$ & $\begin{array}{l}\text { Brincava quando } \\
\text { criança mas } \\
\text { parou }\end{array}$ & $\begin{array}{l}\text { Treinava quando } \\
\text { criança mas } \\
\text { parou }\end{array}$ & $\begin{array}{l}\text { Ainda pratica } \\
\text { ocasionalmente }\end{array}$ & $\begin{array}{l}\text { Joga como } \\
\text { amador } \\
\text { regularmente }\end{array}$ & $\begin{array}{l}\text { Atleta } \\
\text { profissional ou } \\
\text { de alto nível }\end{array}$ \\
\hline 6 & $\begin{array}{l}\text { Envolvimento dos } \\
\text { pais na orientação do } \\
\text { treinamento do filho }\end{array}$ & $\begin{array}{l}\text { Nenhum } \\
\text { envolvimento }\end{array}$ & $\begin{array}{l}\text { Procura ajudar } \\
\text { quando } \\
\text { solicitado }\end{array}$ & $\begin{array}{l}\text { Procura trocar } \\
\text { informações } \\
\text { com o treinador }\end{array}$ & $\begin{array}{l}\text { Dá orientações } \\
\text { para a criança } \\
\text { além do que o } \\
\text { treinador orienta }\end{array}$ & $\begin{array}{l}\text { Como ex-atleta } \\
\text { passa } \\
\text { orientações } \\
\text { e experiências }\end{array}$ & $\begin{array}{l}\text { Profissional da } \\
\text { área e dá } \\
\text { orientação à } \\
\text { criança além } \\
\text { do treinador }\end{array}$ \\
\hline 7 & $\begin{array}{l}\text { Interferência dos pais } \\
\text { na escolha da carreira } \\
\text { profissional do filho }\end{array}$ & $\begin{array}{l}\text { Sugeria } \\
\text { profissões não } \\
\text { relacionadas ao } \\
\text { esporte }\end{array}$ & $\begin{array}{l}\text { Não dava } \\
\text { opinião na } \\
\text { escolha da } \\
\text { carreira } \\
\text { profissional }\end{array}$ & $\begin{array}{l}\text { Sugeria várias } \\
\text { profissões, } \\
\text { incluindo ser } \\
\text { atleta profissional }\end{array}$ & $\begin{array}{l}\text { Queria que } \\
\text { o filho fosse } \\
\text { atleta } \\
\text { profissional }\end{array}$ & & \\
\hline 8 & $\begin{array}{l}\text { Cobrança do estudo } \\
\text { em relação ao esporte }\end{array}$ & $\begin{array}{l}\text { Não relacionava } \\
\text { esporte com o } \\
\text { estudo }\end{array}$ & $\begin{array}{l}\text { Só praticava } \\
\text { esporte se } \\
\text { alcançasse boas } \\
\text { notas }\end{array}$ & $\begin{array}{l}\text { Cobrava } \\
\text { desempenho nos } \\
\text { estudos como } \\
\text { nos esportes }\end{array}$ & $\begin{array}{l}\text { Pratica esporte } \\
\text { mesmo tendo } \\
\text { notas baixas } \\
\text { na escola }\end{array}$ & & \\
\hline 9 & $\begin{array}{l}\text { Atividades extras } \\
\text { diárias relacionadas } \\
\text { ao futebol }\end{array}$ & $\begin{array}{l}\text { Não praticava } \\
\text { nenhuma } \\
\text { atividade extra }\end{array}$ & $\begin{array}{l}\text { Tinha que ser } \\
\text { incentivado para } \\
\text { atividades extras }\end{array}$ & $\begin{array}{l}\text { Brincava de vez } \\
\text { em quando }\end{array}$ & $\begin{array}{l}\text { O tempo livre } \\
\text { era dedicado a } \\
\text { atividades } \\
\text { com bola }\end{array}$ & & \\
\hline & $\begin{array}{l}0 \text { Mudanças na rotina } \\
\text { dos pais em função } \\
\text { da prática esportiva } \\
\text { do filho }\end{array}$ & $\begin{array}{l}\text { Nenhuma } \\
\text { mudança } \\
\text { foi feita }\end{array}$ & $\begin{array}{l}\text { Mudanças nos } \\
\text { horários de } \\
\text { afazeres para } \\
\text { facilitar o esporte }\end{array}$ & $\begin{array}{l}\text { Mudou de } \\
\text { serviço para se } \\
\text { adequar ao } \\
\text { esporte do filho }\end{array}$ & $\begin{array}{l}\text { Mudança de } \\
\text { cidade para facilitar } \\
\text { o desenvolvimento } \\
\text { no esporte }\end{array}$ & & \\
\hline 11 & $\begin{array}{l}1 \text { Com qual freqüência } \\
\text { você se encontra } \\
\text { com seu filho }\end{array}$ & $\begin{array}{l}\text { Uma vez a } \\
\text { cada três meses } \\
\text { ou mais }\end{array}$ & $\begin{array}{l}\text { Uma vez } \\
\text { por mês }\end{array}$ & $\begin{array}{l}\text { Uma vez } \\
\text { por semana }\end{array}$ & Todos os dias & & \\
\hline
\end{tabular}

